\title{
Matching-Adjusted Indirect Comparison of Crisaborole Ointment $2 \%$ vs. Topical Calcineurin Inhibitors in the Treatment of Patients with Mild-to-Moderate Atopic Dermatitis
}

\author{
Howard Thom (D) · Vincent Cheng • Edna Keeney · Maureen P. Neary • \\ Anthony Eccleston · Chuanbo Zang · Joseph C. Cappelleri • \\ Amy Cha $\cdot$ Jacob P. Thyssen
}

Received: October 11, 2021 / Accepted: November 11, 2021 / Published online: December 8, 2021

(C) The Author(s) 2021

\begin{abstract}
Introduction: Crisaborole topical ointment, $2 \%$, is a nonsteroidal, topical anti-inflammatory phosphodiesterase-4 (PDE4) inhibitor that is approved for the treatment of mild-to-moderate atopic dermatitis (AD). The objective of the current analysis was to compare the efficacy of crisaborole $2 \%$ relative to pimecrolimus $1 \%$, tacrolimus $0.03 \%$ and tacrolimus $0.1 \%$ in
\end{abstract}

Supplementary Information The online version contains supplementary material available at https:// doi.org/10.1007/s13555-021-00646-1.

H. Thom $(\bowtie) \cdot$ V. Cheng · E. Keeney

Bristol Medical School, University of Bristol, Bristol, UK

e-mail: howard.thom@bristol.ac.uk

H. Thom · V. Cheng · E. Keeney

Clifton Insight, Bristol, UK

M. P. Neary · C. Zang

Pfizer Inc., Collegeville, PA, USA

A. Eccleston

Pfizer Ltd., London, UK

J. C. Cappelleri

Pfizer Inc., Groton, CT, USA

A. Cha

Pfizer Inc., New York, NY, USA

J. P. Thyssen

Bispebjerg Hospital, University of Copenhagen,

Copenhagen, UK patients aged $\geq 2$ years with mild-to-moderate $\mathrm{AD}$ by comparing improvement in Investigator's Static Global Assessment scores ( (ISGA scores of $0 / 1$ indicating "clear or almost clear"). ISGA was selected as the primary efficacy outcome given the US Food and Drug Administration's recommendations on the use of ISGA for assessment of global severity in $\mathrm{AD}$ and to align with efficacy measurements in the crisaborole registration trials. Safety endpoints could not be analyzed due to differences in outcome definitions across studies.

Methods: Efficacy of crisaborole was evaluated using individual patient data (IPD) from two pivotal phase III randomized controlled trials (RCTs), and efficacy of comparators was evaluated using published RCTs included in a previous network meta-analysis. Vehicle controls were not comparable due to differences in ingredients and population imbalance and, therefore, an unanchored matching-adjusted indirect comparison (MAIC) was used, which reweighted IPD for crisaborole to estimate absolute response in comparator populations.

Results: The odds of achieving an improvement in ISGA score was higher with crisaborole $2 \%$ versus pimecrolimus $1 \%$ (odds ratio [OR] 2.03; 95\% confidence interval [CI] 1.45-2.85; effective sample size $=627$, reduced from 1021; $p$ value $<0.001)$ and for crisaborole $2 \%$ versus tacrolimus $0.03 \%$ (OR 1.50; 95\% CI 1.09-2.05; effective sample size $=311$, reduced from 1021; $p=0.012$ ). 
Conclusion: The unanchored MAIC suggests that the odds of achieving an improvement in ISGA score is greater with crisaborole $2 \%$ than with pimecrolimus $1 \%$ or tacrolimus $0.03 \%$ in patients aged $\geq 2$ years with mild-to-moderate AD. These results are consistent with findings from the previously published network metaanalysis, which used a different methodology for performing indirect treatment comparisons.

Keywords: Atopic dermatitis; Calcineurin inhibitors; Crisaborole; Matching-adjusted indirect comparison; Topical calcineurin inhibitors; Topical corticosteroids

\section{Key Summary Points}

\section{Why carry out this study?}

Crisaborole is a phosphodiesterase- 4 inhibitor that is approved in multiple regions/countries globally for the treatment of mild-to-moderate atopic dermatitis (AD). There are no head-tohead randomized controlled trial (RCT) data currently available on the efficacy and safety of crisaborole versus comparator agents (particularly, topical calcineurin inhibitors) for use by healthcare decision-makers.

This analysis compared the efficacy of crisaborole $2 \%$ to that of several other $\mathrm{AD}$ treatments by using the unanchored matching-adjusted indirect comparison (MAIC) method, which reweighted individual patient data (IPD) for crisaborole to estimate absolute response in comparator populations

\section{What was learned from the study}

The results of the unanchored MAIC suggest that the odds of achieving an Investigator's Static Global Assessment/ Investigator Global Assessment (ISGA/ IGA) scores of 0/1 ("clear or almost clear") is greater with crisaborole $2 \%$ than with pimecrolimus $1 \%$ or tacrolimus $0.03 \%$ in patients aged $\geq 2$ years with mild-tomoderate $\mathrm{AD}$.
The results from this unanchored MAIC are consistent with the findings from a previously published network metaanalysis that used a different methodology for conducting indirect treatment comparisons and included adjustment for heterogeneity of vehicle effect.

The results from this unanchored MAIC may help to inform clinicians and healthcare decision-makers in the management of AD.

\section{INTRODUCTION}

Atopic dermatitis (AD) is a chronic inflammatory skin condition that affects up to $20 \%$ of children and $3 \%$ of adults $[1,2]$, with most of those affected having mild-to-moderate disease severity [3]. Treatment guidelines recommended by the American Academy of Dermatology in 2014 include topical corticosteroids (TCS) and topical calcineurin inhibitors (TCIs) for mild $\mathrm{AD}$, phototherapy for the management of mild and moderate cases of $\mathrm{AD}$ [4], and biologics and immunosuppressants for moderateto-severe disease $[5,6]$. The European Academy of Dermatology and Venereology (EADV) consensus-based guidelines from 2018 and EADV position paper from 2020 also make similar recommendations relative to the role of TCS, TCIs, biologics and immunosuppressants in management of AD according to severity $[7,8]$.

A novel way to manage $\mathrm{AD}$ is to inhibit phosphodiesterase-4 (PDE4), an enzyme that is associated with a pro-inflammatory response and cytokine release [9]. Crisaborole topical ointment, $2 \%$, is a nonsteroidal, topical antiinflammatory PDE4 inhibitor that is approved for the treatment of mild-to-moderate AD [10]. No head-to-head randomized controlled trials (RCTs) are available to evaluate efficacy and safety of crisaborole versus TCIs, despite comparative data being required for healthcare decision-making and evaluations for reimbursement and access. 
To address this evidence gap, a network meta-analysis (NMA) was performed which showed that crisaborole $2 \%$ was superior to vehicle and pimecrolimus $1 \%$ and comparable to tacrolimus 0.1 or $0.3 \%$ at $28-42$ days in patients aged $\geq 2$ years with mild-to-moderate $\mathrm{AD}$ in terms of the efficacy outcome Investigator's Static Global Assessment (ISGA) 5-point rating scale scores of "clear or almost clear" (ISGA 0/1) [2]. Safety outcomes were not compared because of differences in reporting (e.g. thresholds used), outcome definitions and study publication dates, which are common issues in indirect comparisons [11]. The efficacy analyses in the NMA required an adjustment for variations in vehicle response rates across studies included in the NMA. This variation in vehicle response is partly explained by differences in their active ingredients [12] and, therefore, they cannot be viewed as a placebo. For example, the base ointment of crisaborole $2 \%$ contains propylene glycol, a well-known humectant commonly used in skin care formulations, and emollients, such as soft paraffin and hard paraffin [13]. In vehicle-controlled RCTs assessing similar populations with mildto-moderate $\mathrm{AD}, 40.6 \%$ and $29.7 \%$ of vehicletreated patients achieved the endpoint of ISGA $0 / 1$ at 4 weeks of treatment in each of two crisaborole comparator studies versus only $19.5 \%$ of vehicle-treated patients achieving this endpoint in a tacrolimus comparator study $[14,15]$.

Baseline risk regression was used in the previous NMA to adjust for differences in vehicle response, but the heterogeneity is such that the evidence network is not truly connected via vehicle [16]. In such cases, the unanchored matching-adjusted indirect comparison (MAIC) method has been recommended in the literature and by healthcare payers, including the UK National Institute for Health and Care Excellence (NICE) $[17,18]$. This statistical approach does not use vehicle controls, but instead adjusts for imbalances in effect modifiers and prognostic factors using individual patient data (IPD) for crisaborole and aggregated data for comparators from published trials (previously included in the NMA).

The objective of the current analysis was to compare treatments using the unanchored
MAIC method [18, 19], in which efficacy results between crisaborole $2 \%$ with pimecrolimus $1 \%$, tacrolimus $0.03 \%$ and tacrolimus $0.1 \%$ were assessed in patients aged $\geq 2$ years who had mild-to-moderate AD.

\section{METHODS}

\section{Systematic Literature Search}

The efficacy of crisaborole and comparator drugs were evaluated from published randomized clinical studies that were included in the NMA. The process for selecting articles and for extracting data was published previously [2]. The selected studies included a mix of pediatric and adult populations and is described in detail in this prior publication [2]. The comparator studies included those for pimecrolimus $1 \%$ [20-23], tacrolimus $0.03 \%[15,20,21,24]$ and tacrolimus $0.1 \%$ [22].

\section{Statistical Analysis via the Unanchored MAIC}

Because vehicle controls in the identified studies are not comparable, anchored indirect comparison or NMA would be biased $[12,17]$. The UK healthcare decision maker (NICE) recommends the use of unanchored populationadjusted indirect comparisons, which accommodate for study differences when common comparators cannot be used to perform anchored indirect comparisons $[17,18]$. In this analysis, MAIC was utilized, which did not include vehicle controls [19]. The ISGA and Investigator's Global Assessment (ISGA/IGA $0 / 1$ ) at 28-42 days were chosen to measure efficacy given that the registration studies for crisaborole used the ISGA to evaluate efficacy and that most of the RCTs on comparators reported these outcome measures.

Other measures of efficacy and severity, such as the Eczema Area and Severity Index (EASI) and SCORing Atopic Dermatitis (SCORAD), were not included in the crisaborole registration studies. Utilizing ISGA as the primary outcome aligns with the previously published NMA [2], 
and with the guidance from the US Food and Drug Administration that recommends ISGA for the assessment of global disease severity in $\mathrm{AD}$ [25].

The estimator of the relative effect between intervention A (i.e. crisaborole) and comparator B (e.g. pimecrolimus or tacrolimus) in the population of the RCT on B is

$$
\widehat{d}_{A B(B)}=\mathrm{g}\left(\widehat{Y}_{A(B)}\right)-\mathrm{g}\left(\widehat{Y}_{B(B)}\right),
$$

where $\widehat{Y}_{A(B)}$ is the estimator of absolute response on $\mathrm{A}$ in the comparator $\mathrm{B}$ population, $\widehat{Y}_{B(B)}$ is the reported absolute response of $\mathrm{B}$ in the $\mathrm{B}$ population and $g()$ is a link function to a scale on which treatment effects are additive (i.e. the linear predictor scale). In the current analysis, absolute response was the proportion of patients achieving ISGA/ IGA $0 / 1$ and $g()$ was a logistic link function converting to the log odds scale. The MAIC estimator $\widehat{Y}_{A(B)}$ uses propensity scores, themselves estimated by logistic regression on patient characteristics to reweight the IPD for intervention $\mathrm{A}$, so the distribution of effect modifiers and prognostic variables are matched to the $\mathrm{B}$ population $[17,18]$.

This process involves two steps: (1) IPD were reweighted to ensure that covariate distributions in the trial on treatment $A$ match the population of comparator B; and (2) the estimated weights were used to calculate $\widehat{Y}_{A(B)}$. The effective sample size (ESS) for each comparison is estimated using patient weights; these are always reduced from the total sample on crisaborole (i.e. 1021 patients), and lower values indicate poor overlap with comparator trials and overreliance on a subset of patients.

A histogram of patients' weights was also generated to test for overreliance on a subset, which would be indicated by extreme weights for a small number of patients. Patient characteristics before and after matching were compared between crisaborole and comparator RCTs to assess the success of the reweighting process. An unweighted "naïve" estimator $\widehat{Y}_{A(A)}$ (i.e. absolute response in the A population) was used as a sensitivity analysis.
When multiple comparator studies were available, $\widehat{Y}_{B(B)}$ was the output of a random effects meta-analysis. The weights of this metaanalysis were used to form weighted averages of proportion, mean and standard deviations (SD) of baseline characteristics across comparator studies, to which the IPD were then matched. Unanchored MAIC was conducted in R based on recommendations from NICE [18]. The 'sandwich' package was used to generate effect estimates as it correctly propagates uncertainty in patient propensity scores through to relative effect estimates. Results are summarized as odds ratios on ISGA/IGA $0 / 1$ for crisaborole versus comparators. Two-sided $p$ values and 95\% confidence intervals were calculated by assuming the log odds of ISGA/IGA 0/1 followed a normal distribution.

NICE and published literature recommend that all effect modifiers and prognostic variables be included in the logistic regression used to estimate propensity scores for unanchored MAIC $[17,18]$. Effect modifiers and prognostic variables were identified through a literature review, expert clinical opinion and regression analyses (Electronic Supplementary Material Files 1-3), a triangulation approach previously used for MAIC in psoriatic arthritis. Identified variables to match, when reported, were age (mean and SD), proportion male, proportion Caucasian, percentage body surface area, ISGA/ IGA score, proportion receiving prior TCI and proportion receiving prior TCS. Characteristics not reported by both the crisaborole and the comparator trial were omitted from the propensity score regression model.

\section{Ethics Compliance}

This article is based on data from previously conducted studies and does not contain any studies with human participants or animals performed by any of the authors.

\section{RESULTS}

The evidence for higher odds of achieving an ISGA $0 / 1$ improvement was evident for 


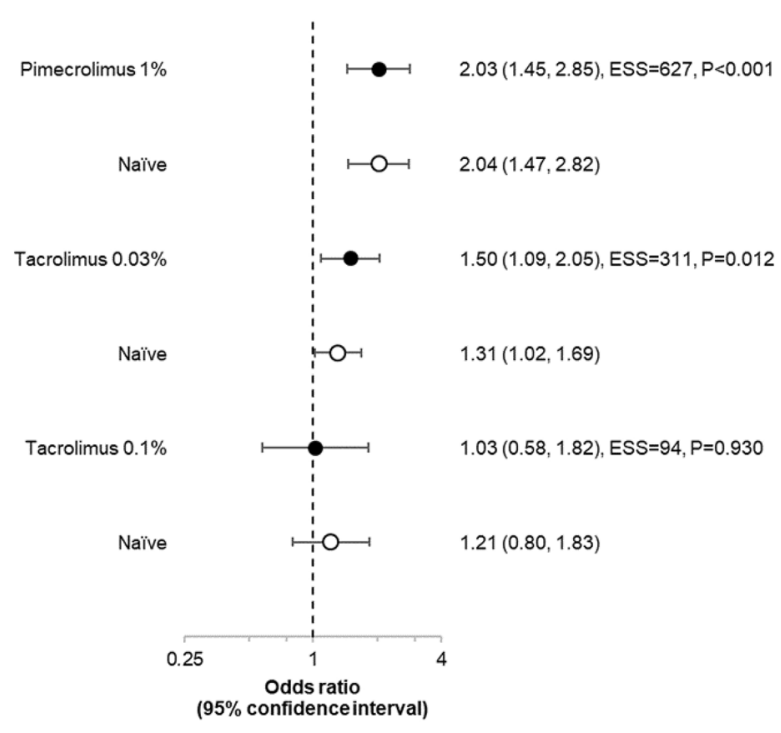

Fig. 1 Odds ratio (95\% confidence interval) and twosided $p$ values of achieving an Investigator's Static Global Assessment improvement score of 0-1 (ISGA 0/1) with crisaborole versus pimecrolimus $1 \%$, tacrolimus $0.03 \%$ and tacrolimus $0.1 \%$. ESS Estimated effect size

crisaborole $2 \%$ versus pimecrolimus $1 \%$ (OR 2.03; 95\% CI 1.45-2.85; ESS = 627, reduced from 1021; $p$ value $<0.001$ ) and also evident for crisaborole versus tacrolimus $0.03 \%$ (OR 1.50; 95\% CI 1.09-2.05; $\mathrm{ESS}=311$, reduced from 1021; $p=0.012$ ) (Fig. 1). Unweighted naïve comparisons were similar to the estimated effect size findings.

Comparison of crisaborole versus tacrolimus $0.1 \%$ was infeasible due to a large reduction in ESS (to 94) and highly skewed patient weights histogram (Fig. 2), indicating an over-reliance on a small subset of crisaborole patients and poor overlap between trials.

Crisaborole $2 \%$ versus pimecrolimus $1 \%$ MAIC gave similar weight to a large proportion of the population and had no clear outliers (Fig. 2).

The crisaborole $2 \%$ versus tacrolimus $0.03 \%$ comparison gave zero weight to a larger proportion, which was reflected by the lower effective sample size, but was not very reliant on a small subset.

A comparison of patient characteristics before and after matching crisaborole $2 \%$ to pimecrolimus $1 \%$ and to tacrolimus $0.03 \%$ was made. Good quality matching was evident in both the means and, for the case of age, standard deviations (Tables 1, 2). However, the potentially important characteristics of ISGA at baseline, prior TCI use and prior TCS use were not reported by any comparator RCT so there was no feasibility for matching them.

\section{DISCUSSION}

This study sought to compare the efficacy of crisaborole $2 \%$ with pimecrolimus $1 \%$, tacrolimus $0.03 \%$ and tacrolimus $0.1 \%$, in patients with mild-to-moderate $\mathrm{AD}$ using the MAIC method. The findings showed that crisaborole $2 \%$ had higher odds of achieving ISGA/IGA 0/1 at 6 weeks than tacrolimus $0.03 \%$ or pimecrolimus $1 \%$. Comparison with tacrolimus $0.01 \%$ was infeasible due to limited overlap between the crisaborole $2 \%$ and tacrolimus $0.01 \%$ RCTs, indicated by an ESS reduction from 1021 to 94.

In the NMA, lack of connected networks (comparability of vehicle controls) and balance of effect modifiers supported the use of an unanchored MAIC. The strength of this study design is that it aligns with the NICE guidelines for population adjusted indirect comparison methods when head-to-head RCTs are not available and when networks are disconnected. The methodology was closely aligned to those presented in NICE Decision Support Unit Technical Support Document 18 [18], and the indirect comparisons were assessed on a linear predictor scale of log odds ratios.

Our choice of the method MAIC occurred before the recent publication of simulation studies indicating that simulated treatment comparison may be less biased [26]. However, this simulation study was only conducted for the anchored case (i.e. when vehicle control could be used) and not the unanchored case (i.e. our situation, where only single arms from RCTs were used). Therefore, the relevance of the method to the current research is unclear. A more relevant simulation study is that of Hatswell et al. [27] which found that unanchored MAIC can reduce bias and produce valid comparisons if patient numbers are not low. 


\section{Pimecrolimus 1\%}

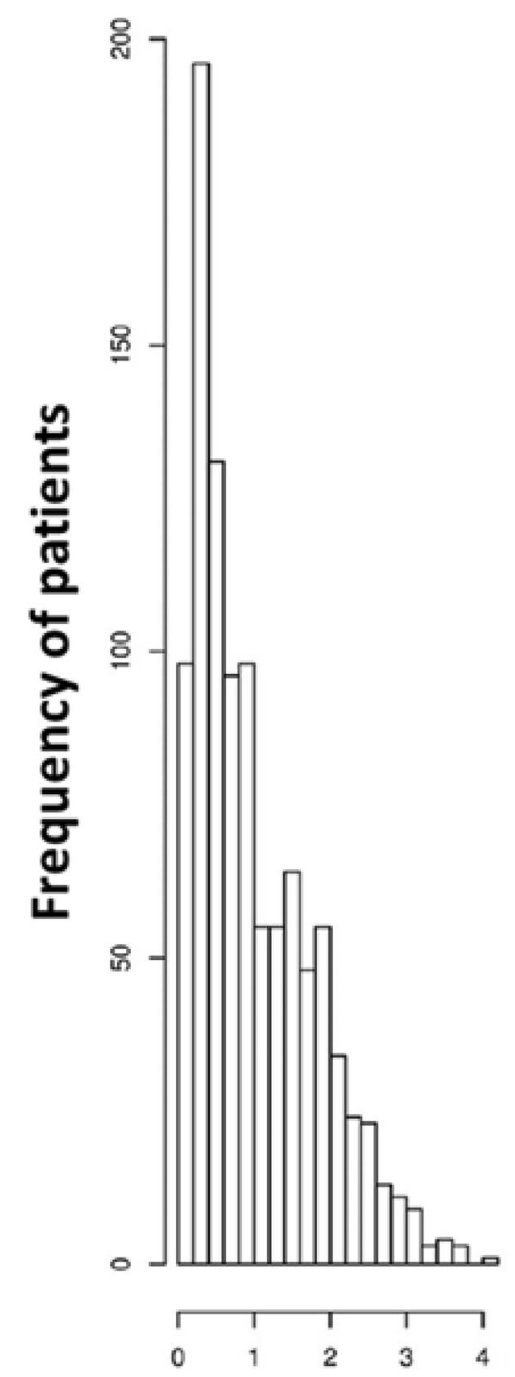

Tacrolimus $\mathbf{0 . 0 3 \%}$

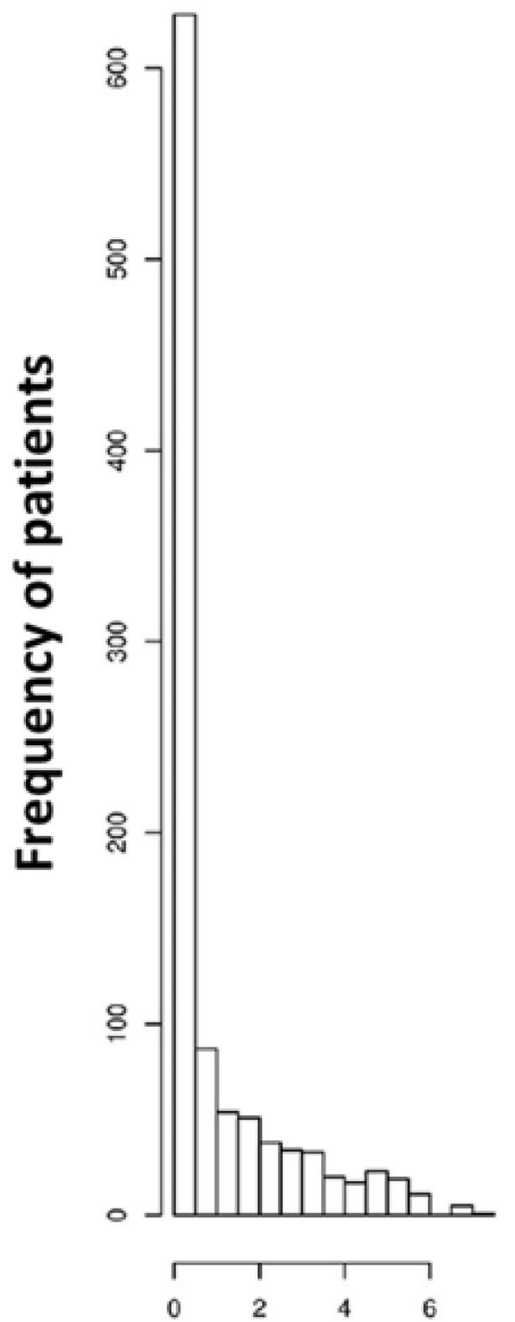

Patient weights

\section{Tacrolimus $\mathbf{0 . 1 \%}$}

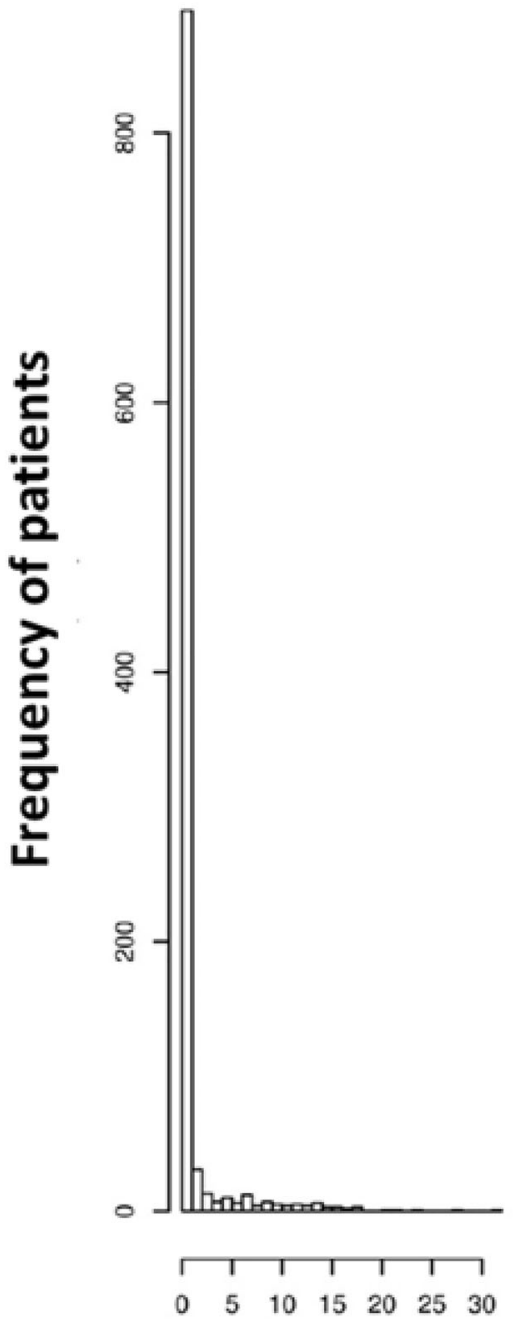

Fig. 2 Patient weights histograms for unanchored matched-adjusted indirect comparison

As with all studies, some limitations should be acknowledged. Potential effect modifiers or prognostic variables, including family history, use of emollients, lesion characteristics or other allergic comorbidities, were not recorded in certain datasets. Published studies may have lacked standardization on how IGA was implemented, and hence direct comparison between studies was not feasible [28].
Although the weighting of the unanchored MAIC provides an indirect comparison of treatments in the same population, the patients eligible to receive crisaborole may not align with comparator populations; this raises the need for head-to-head trials to compare treatment groups and to reduce the need for indirect comparisons. Moreover, a comparison on odds ratios of achieving ISGA/IGA 0/1, rather than mean differences in ISGA/IGA, limits clinical 
Table 1 Comparison of matching variables (effect modifiers or prognostic variables) before and after matching to pimecrolimus $1 \%$ randomized controlled trials

\begin{tabular}{llll}
\hline $\begin{array}{l}\text { Variables (effect modifiers or prognostic } \\
\text { variables) }\end{array}$ & $\begin{array}{l}\text { Crisaborole mean before } \\
\text { matching }\end{array}$ & $\begin{array}{l}\text { Crisaborole mean after } \\
\text { matching }\end{array}$ & $\begin{array}{l}\text { Comparator } \\
\text { mean }\end{array}$ \\
\hline Age (SD) & $12.29(12.14)$ & $13.60(6.75)$ & $13.60(6.62)$ \\
Proportion male & 0.44 & 0.45 & 0.45 \\
Proportion Caucasian & 0.61 & 0.52 & 0.52 \\
\% BSA & 0.18 & 0.19 & 0.19 \\
ISGA & 0.61 & 0.62 & Not reported \\
Proportion prior TCI & 0.03 & 0.04 & Not reported \\
Proportion prior TCS & 0.38 & 0.36 & Not reported \\
\hline
\end{tabular}

$B S A$ Body surface area, ISGA Investigator's Static Global Assessment, $S D$ standard deviation, $T C I$ topical calcineurin inhibitors, TCS topical corticosteroids

Table 2 Comparison of matching variables (effect modifiers or prognostic variables) before and after matching to tacrolimus $0.03 \%$ randomized controlled trials

\begin{tabular}{llll}
\hline $\begin{array}{l}\text { Variables (effect modifiers or prognostic } \\
\text { variables) }\end{array}$ & $\begin{array}{l}\text { Crisaborole mean before } \\
\text { matching }\end{array}$ & $\begin{array}{l}\text { Crisaborole mean after } \\
\text { matching }\end{array}$ & $\begin{array}{l}\text { Comparator } \\
\text { mean }\end{array}$ \\
\hline Age (SD) & $12.29(12.14)$ & $15.35(4.97)$ & $15.35(3.91)$ \\
Proportion male & 0.44 & 0.43 & 0.43 \\
Proportion Caucasians & 0.61 & 0.59 & 0.59 \\
\% BSA & 0.18 & 0.12 & 0.12 \\
ISGA & 0.61 & 0.56 & Not reported \\
Proportion prior TCI & 0.03 & 0.04 & Not reported \\
Proportion prior TCS & 0.38 & 0.32 & Not reported \\
\hline
\end{tabular}

Tacrolimus 0.03\% arms from Kempers et al. [20], Chapman et al. [24], Paller et al. [21] and Levy et al. [29]

interpretability as a minimum clinically important difference is difficult to specify. Alternative outcomes, such as SCORAD and EASI, were not collected in the crisaborole RCTs, and it was thus infeasible to compare with pimecrolimus or tacrolimus on these outcomes. Pruritus data were collected during crisaborole RCTs, although a standard instrument was not used and, therefore, the results for pruritus could not be evaluated in comparison to other studies.

The ESS indicated a moderate reduction (from 1021 to 627) when comparing crisaborole
$2 \%$ with pimecrolimus $1 \%$ but a more substantial reduction (from 1021 to 311) when compared with tacrolimus $0.03 \%$. Thus, the MAIC comparison with tacrolimus $0.03 \%$ was based on a limited subset of the crisaborole RCT population.

The indirect comparison methods used in the current study and a previous study [2] are accepted as reliable and robust methods by NICE guidelines [18] although these methods cannot replace a head-to-head comparison in a randomized controlled trial (not currently available), when determining superiority. 
Therefore, caution should be used when interpreting the results of the current study.

\section{CONCLUSION}

Unanchored MAIC suggests that the odds of achieving an ISGA/IGA $0 / 1$ is greater with crisaborole $2 \%$ than with pimecrolimus $1 \%$ or tacrolimus $0.03 \%$ in patients aged $\geq 2$ years with mild-to-moderate $\mathrm{AD}$. This is consistent with the findings from the previously published NMA, which had used a different methodology for the conduct of indirect treatment comparisons and included adjustment for heterogeneity of vehicle effect. These results may provide useful evidence for clinicians and health care decision-makers in the management of $\mathrm{AD}$.

\section{ACKNOWLEDGEMENTS}

Funding. This study was sponsored by Pfizer Inc. Pfizer Inc. is also funding the journal's Rapid Service fee.

Medical Writing Assistance. Editorial/medical writing support was provided by Katie Crosslin, PhD, and Holly Richendrfer, PhD at Evidera and was funded by Pfizer Inc. (New York, NY, USA).

Authorship. All named authors meet the International Committee of Medical Journal. Editors (ICMJE) criteria for authorship for this manuscript, take responsibility for the integrity of the work as a whole and have provided final approval of the version to be published.

Author Contributions. HT, VC, EK and JCC have made substantial contributions to the conception/design. HT, VC and EK have made substantial contributions to the data acquisition and analysis. All authors have made substantial contributions to the interpretation of data for the work, drafting of the work and critical revision of the article for important intellectual content. All authors have provided final approval of the manuscript.
Prior Presentation. Some of the data in this manuscript have appeared in a poster presented at the International Society for Pharmacoeconomics and Outcomes Research 22nd Annual European Congress; 2-6 November 2019; Copenhagen, Denmark: Fahrbach K, Tarpey J, Bergrath E, et al. A systematic literature review and network meta-analysis (NMA) of crisaborole $2 \%$ ointment for the treatment of mild-tomoderate atopic dermatitis (AD). Value Health. 2019;22 (Suppl 3):S597-S598. Abstract PDG6.

Disclosures. Howard Thom has received personal consulting fees from Pfizer Inc., Eisai Co. Ltd, Lundbeck, Argenx, Novartis Pharma AG, Roche Holding AG, Bayer AG, BMS and Janssen Pharmaceuticals. Vincent Cheng has received personal consulting fees from Pfizer Inc. and BMS. Edna Keeney has received personal consulting fees from BMS, Pfizer Inc. and Roche Holding AG. Amy Cha, Joseph C. Cappelleri, Maureen P. Neary and Chuanbo Zang are employed by Pfizer Inc. and own Pfizer stock and/or stock options. Anthony Eccleston is employed by Pfizer Ltd and owns Pfizer stock and/or stock options. Jacob P. Thyssen is an advisor/investigator or speaker for Pfizer Inc., AbbVie, Eli Lilly and Company, Almirall, LEO Pharma, Regeneron and Sanofi-Genzyme. Evidera received funding from Pfizer Inc. to develop this manuscript.

Compliance with Ethics Guidelines. This article is based on data from previously conducted studies and does not contain any studies with human participants or animals performed by any of the authors.

Data Availability. Upon request, and subject to review, Pfizer will provide the data that support the findings of this study. Subject to certain criteria, conditions and exceptions, Pfizer may also provide access to the related individual anonymized participant data. See http:// www.pfizer.com/science/clinical-trials/trialdata-and-results for more information.

Open Access. This article is licensed under a Creative Commons Attribution-NonCommercial 4.0 International License, which permits 
any non-commercial use, sharing, adaptation, distribution and reproduction in any medium or format, as long as you give appropriate credit to the original author(s) and the source, provide a link to the Creative Commons licence, and indicate if changes were made. The images or other third party material in this article are included in the article's Creative Commons licence, unless indicated otherwise in a credit line to the material. If material is not included in the article's Creative Commons licence and your intended use is not permitted by statutory regulation or exceeds the permitted use, you will need to obtain permission directly from the copyright holder. To view a copy of this licence, visit http://creativecommons.org/licenses/by$\mathrm{nc} / 4.0 /$.

\section{REFERENCES}

1. Mayba JN, Gooderham MJ. Review of atopic dermatitis and topical therapies. J Cutan Med Surg. 2017;21(3):227-36.

2. Fahrbach K, Tarpey J, Washington EB, et al. Crisaborole ointment, $2 \%$, for treatment of patients with mild-to-moderate atopic dermatitis: systematic literature review and network meta-analysis. Dermatol Ther (Heidelb). 2020;10(4):681-94.

3. Zane L, Chanda S, Jarnagin K, Nelson D, Spelman L, Gold LS. Crisaborole and its potential role in treating atopic dermatitis: overview of early clinical studies. Immunotherapy. 2016;8(8):853-66.

4. American Academy of Dermatology. Management of atopic dermatitis: guideline from the American Academy of Dermatology. Am Fam Physician. 2014;90(11):798-9.

5. Ring J, Alomar A, Bieber T, et al. Guidelines for treatment of atopic eczema (atopic dermatitis) Part II. J Eur Acad Dermatol Venereol. 2012;26(9): 1176-93.

6. Wollenberg A, Christen-Zäch S, Taieb A, et al. ETFAD/EADV Eczema task force 2020 position paper on diagnosis and treatment of atopic dermatitis in adults and children. J Eur Acad Dermatol Venereol. 2020;34(12):2717-44.

7. Wollenberg A, Barbarot S, Bieber T, et al. Consensus-based European guidelines for treatment of atopic eczema (atopic dermatitis) in adults and children: part I. J Eur Acad Dermatol Venereol. 2018;32(5):657-82.

8. Wollenberg A, Barbarot S, Bieber T, et al. Consensus-based European guidelines for treatment of atopic eczema (atopic dermatitis) in adults and children: part II. J Eur Acad Dermatol Venereol. 2018;32(6):850-78.

9. Guttman-Yassky E, Hanifin JM, Boguniewicz M, et al. The role of phosphodiesterase 4 in the pathophysiology of atopic dermatitis and the perspective for its inhibition. Exp Dermatol. 2019;28(1):3-10.

10. Canadian Agency for Drugs and Technologies in Health. Common drug reviews. Clinical review report: crisaborole ointment, 2\% (Eucrisa): (Pfizer Canada Inc): indication: for topical treatment of mild to moderate atopic dermatitis in patients 2 years of age and older. Ottawa: Canadian Agency for Drugs and Technologies in Health; 2019. https://www.ncbi.nlm.nih.gov/books/NBK542348/. Accessed 30 Aug 2021.

11. Bennetts M, Whalen E, Ahadieh S, Cappelleri JC. An appraisal of meta-analysis guidelines: how do they relate to safety outcomes? Res Synth Methods. 2017;8(1):64-78.

12. Danby SG, Draelos ZD, Gold LFS, et al. Vehicles for atopic dermatitis therapies: more than just a placebo. J Dermatol Treat. 2020. https://doi.org/10. 1080/09546634.2020.1789050.

13. Gesslein BW. Humectants in personal care formulation: a practical guide. Conditioning agents for hair and skin. Berlin: CRC Press; 1999.

14. Paller AS, Tom WL, Lebwohl MG, et al. Efficacy and safety of crisaborole ointment, a novel, nonsteroidal phosphodiesterase 4 (PDE4) inhibitor for the topical treatment of atopic dermatitis (AD) in children and adults. J Am Acad Dermatol. 2016;75(3):494-503.e6.

15. Schachner LA, Lamerson C, Sheehan MP, et al. Tacrolimus ointment $0.03 \%$ is safe and effective for the treatment of mild to moderate atopic dermatitis in pediatric patients: results from a randomized, double-blind, vehicle-controlled study. Pediatrics. 2005;116(3):e334-42.

16. Rücker G, Schmitz S, Schwarzer G. Component network meta-analysis compared to a matching method in a disconnected network: a case study. Biom J. 2021;63(2):447-61.

17. Phillippo DM, Ades AE, Dias $S$, Palmer $S$, Abrams KR, Welton NJ. Methods for population-adjusted indirect comparisons in health technology appraisal. Med Decis Mak. 2018;38(2):200-11. 
18. Phillippo DM AA, Dias S, Palmer S, Abrams KR, Welton NJ. NICE DSU technical support document 18: methods for population-adjusted indirect comparisons in submissions to NICE. 2016. http://www. nicedsu.org.uk/wp-content/uploads/2017/05/ Population-adjustment-TSD-FINAL.pdf. Accessed 30 Aug 2021.

19. Signorovitch JE, Sikirica V, Erder $\mathrm{MH}$, et al. Matching-adjusted indirect comparisons: a new tool for timely comparative effectiveness research. Value Health. 2012;15(6):940-7.

20. Kempers S, Boguniewicz M, Carter E, et al. A randomized investigator-blinded study comparing pimecrolimus cream $1 \%$ with tacrolimus ointment $0.03 \%$ in the treatment of pediatric patients with moderate atopic dermatitis. J Am Acad Dermatol. 2004;51(4):515-25.

21. Paller AS, Lebwohl M, Fleischer AB Jr, et al. Tacrolimus ointment is more effective than pimecrolimus cream with a similar safety profile in the treatment of atopic dermatitis: results from 3 randomized, comparative studies. J Am Acad Dermatol. 2005;52(5):810-22.

22. Abramovits W, Fleischer AB Jr, Jaracz E, Breneman D. Adult patients with moderate atopic dermatitis: tacrolimus ointment versus pimecrolimus cream. J Drugs Dermatol. 2008;7(12):1153-8.

23. Eichenfield LF, Lucky AW, Boguniewicz M, et al. Safety and efficacy of pimecrolimus (ASM 981) cream $1 \%$ in the treatment of mild and moderate atopic dermatitis in children and adolescents. J Am Acad Dermatol. 2002;46(4):495-504.

24. Chapman MS, Schachner LA, Breneman D, et al. Tacrolimus ointment $0.03 \%$ shows efficacy and safety in pediatric and adult patients with mild to moderate atopic dermatitis. J Am Acad Dermatol. 2005;53(2 Suppl 2):S177-85.

25. US Food and Drug Administration. Draft guidance on pimecrolimus. 2012. https://www.accessdata. fda.gov/drugsatfda_docs/psg/Pimecrolimus_cr_1_ 21302_RC03-12.pdf. Accessed 30 Aug 2021.

26. Phillippo DM, Dias S, Ades AE, Welton NJ. Assessing the performance of population adjustment methods for anchored indirect comparisons: a simulation study. Stat Med. 2020;39(30):4885-911.

27. Hatswell AJ, Freemantle N, Baio G. the effects of model misspecification in unanchored matchingadjusted indirect comparison: results of a simulation study. Value Health. 2020;23(6):751-9.

28. Futamura M, Leshem YA, Thomas KS, Nankervis $H$, Williams HC, Simpson EL. A systematic review of Investigator Global Assessment (IGA) in atopic dermatitis (AD) trials: many options, no standards. J Am Acad Dermatol. 2016;74(2):288-94.

29. Levy A, Sheehan M, Roberts R. Tacrolimus cream $0.03 \%$ is safe and effective in the treatment of mild to moderate atopic dermatitis in adults. J. Allergy Clin. Immunol. 2005;115(2):S103. 